\title{
50 years of Neuroradiology
}

\section{Rüdiger von Kummer ${ }^{1}$}

Published online: 6 December 2019

(C) Springer-Verlag GmbH Germany, part of Springer Nature 2019

Welcome to the second decade of the twenty-first century.

While the President of the European Society of Neuroradiology addresses the future of neuroradiologists in this issue [1], I invite you to look back to 1970 when the first issue of Neuroradiology appeared. Professor Erik Lindgren, one Head of the famous Stockholm School of Neuroradiology, noted on the first pages of our Journal that "Neuroradiology is still such a young speciality that it has not yet been accepted in some countries as an independent discipline" [2]. Lindgren recognized the need for specialized physicians who devoted themselves exclusively to the new field of radiology possessing, "in addition to a good grounding in medicine in general, a satisfactory knowledge of technical aspects, physics, and radiobiology." He further argued that "without doubt, the best result is obtained if both clinician and radiologist, each on the whole working independently of the other, carry their own investigations as far as possible towards a diagnosis" and that "the need for specialization in the field of diagnostic radiology is becoming increasingly evident" [1]. To satisfy the demands for adequate radiological examinations made by new special sections of medicine like neurosurgery and neurology, a separate radiological speciality was required. Lindgren was convinced that the new journal Neuroradiology - would "undoubtedly promote further progress in this field and will strengthen the standing of neuroradiology" [1].

Neuroradiology appeared in April 1970, representing one of the first scientific journals solely devoted to this young medical speciality. Volume 1 consisted of four issues publishing 40 original papers and four editorials. Since 1997, 12 issues per year have been regularly published. In the Journal's second editorial after Lindgren's, Herman Fischgold described the development of neuroradiology from 1922 [3]. Thereafter, D. Gordon Potts addressed the research

Rüdiger von Kummer

Ruediger.vonKummer@uniklinikum-dresden.de

1 Institute of Diagnostic and Interventional Neuroradiology,

Universitätsklinikum Dresden, Fetscherstr, 74

01307 Dresden, Germany activities of neuroradiologists [4], and B.G. Ziedses des Plantes described the clinical responsibilities of neuroradiologists as "more than making nice radiographs of neurological lesions" covering "activities before, during and after the x-ray examination" [5]."

In 1970, computed tomography (CT), magnetic resonance imaging (MRI) and endovascular interventions had yet to be introduced into clinical medicine. Twenty-seven of 40 original Neuroradiology articles published in 1970 dealt with the anatomy and pathology of cerebral vessels as well as angiographic techniques. Additionally, Neuroradiology published eight papers on pneumencephalography findings, among them "Roentgendiagnosis of subdural hygroma in infants", featuring encephalography as the primary methodology [6]. Finally, there were two papers applying early scintigraphy and three each on the use of either ultrasound, myelography with pantopaque or conventional radiography.

In 1972, R. Djindjian tackled "the future for angiography in Neuroradiology", emphasizing the advantages of femoral catherization and its potential as an effective therapeutic method [7]. One year later, he presented the first results of endovascular therapy in Neuroradiology [8]. While indications for endovascular therapy widened steadily during the following years and decades, CT and MRI revolutionized diagnostic neuroradiology by visualizing central nervous system in-vivo tissue. The first CT scan appeared in Neuroradiology in 1975 [9] and the first MRI scan in 1978 [10]. In hindsight, 45 years later, it is hard to understand why J. Bull opened his remarkable editorial on "The changing face of Neuroradiology over nearly forty years" with the comment, "Many younger men are very concerned that Computerized Axial Tomography is virtually destroying neuroradiology" [11]. He wisely continued: "I understand their concern but do not share it". Shortly thereafter, the first neuroradiological observations with CT were published in Neuroradiology [12] and the first clinical observations with MRI were published in 1982 [13].

For 50 years, Neuroradiology has closely followed the revolutionary development of diagnostic and interventional neuroradiology and will continue to do so through challenging 
times of digitalisation in medicine, ultimately strengthening the Journal's standing. I thank our editorial and reviewing team for selecting the best scientific papers in our field. I am grateful for the technical support by our publisher as well as the ideas and criticism provided by the members of the Editorial Board. My special thanks go to those Members who have served for six or more years on our Editorial Board and will now retire to create space for new members.

Prof. Dr. med. Rüdiger von Kummer.

Editor-in-Chief.

\section{References}

1. Van Goethem J (2020) When will neuroradiologists be replaced by robots? Neuroradiology 62: in press

2. Lindgren E (1970) Editorial. Neuroradiology 1:1-3

3. Fischgold H (1970) Editorial. Neuroradiology 1:59-60

4. Potts DG (1970) Research and the Neuroradiologist. Neuroradiology 1:121
5. Ziedses des Plantes BG (1970) Editorial. Neuroradiology 1:187

6. Cronqvist S, Efsing HO (1970) Roentgendiagnosis of subdural hygroma in infants. Neuroradiology 1:61-67

7. Djindjian R (1972) The future for angiography in neuroradiology. Neuroradiology 3:175-176

8. Djindjian R, Cophignon J, Rey A, Théron J, Merland JJ, Houdart R (1973) Superlective arteriographic embolization by the femoral route in neuroradiology. Study of 50 cases. II. Embolization in vertebromedullary pathology. Neuroradiology 6:132-142

9. Smith PR, Peters TM, Müller HR, Elke M (1975) Towards the assessment of the limitations on computerized axial tomography. Neuroradiology 9:1-8

10. Hinshaw WS, Andrew ER, Bottomley PA, Holland GN, Moore WS, Worthington BS (1978) Internal structural mapping by nuclear magnetic resonance. Neuroradiology 16:607-609

11. Bull J (1975) The changing face of neuroradiology over nearly forty years. Neuroradiology 9:111-115

12. Gyldensted C, Kosteljanetz M (1976) Measurements oft the normal ventricular system with computer tomography of the brain. A preliminary study on 44 adults. Neuroradiology 10:205-213

13. Bydder GM, Steiner RE (1982) NMR imaging oft the brain. Neuroradiology 23:231-240

Publisher's note Springer Nature remains neutral with regard to jurisdictional claims in published maps and institutional affiliations. 